\title{
IT Professionals’ Information Behaviour on Twitter
}

\author{
Bazilah A. Talip \\ Queensland University of Technology, Australia. \\ Universiti Kuala Lumpur, Malaysia. \\ bazilah@unikl.edu.my
}

\begin{abstract}
Background. Twitter is widely used as a communication medium, and an electronic word-of-mouth. A literature search found no previous empirical study of microblogging platforms as "places", and how they are used for professional communication and networking.

Objectives. This study aimed to understand information technology (IT)

professionals' information behaviour in microblogging on Twitter.

Methods. The data were collected using online observation and interviews, and analysed using constructivist grounded theory.

Results. Twitter is used by IT professionals mainly for professional networking, professional work and professional development. The data highlighted the interrelatedness of information-sharing and professional networking. Information acts as a trigger to create human networks, as information sharing and information encountering lead to serendipitous discovery of useful IT experts. Twitter is an information ground (Fisher, 2005) where IT professionals encounter not only information but also experts and even work and project opportunities. The more IT professionals share information that is related to his or her expertise, the greater the chance to be noticed and acknowledged as an IT expert.

Significance. The study has shed some light on how Twitter is used for professional networking in a strategic manner to advance professional goals. The findings can assist organisations to better understand and provide for this emerging channel of professional information-sharing for their staff and stakeholders.
\end{abstract}

\section{INTRODUCTION}

Information behaviour is a term used to describe the various ways in which people interact with information and utilise it (Bates, 2005). Information behaviour refers to human behaviour in relation to information, and the explicit, implicit and tacit mental states related to information. The information behaviour literature identifies several discrete information behaviours, such as the recognition of information needs (Belkin, 2008), information seeking (Chatman, 1991), information use (Bartlett \& Toms, 2005), berry-picking (Bates, 1990), and information foraging (Pirolli \& Card, 1999). Much of information behaviour research has focused on individuals' day-to-day information needs rather than information behaviours for professional purposes in online space. In the information age, the use of microblogs has significantly transformed the way people seek and use information (Power, 2015). The 
microblogging phenomenon has also influenced information behaviours, but this influence has not yet been considered in relation to the existing information behaviour models. In the digital age, professionals use information that is available on the Internet creatively, and share it as posts on social media. The audience who can access and read these posts are much wider than the audience of traditional word-of-mouth information sharing or dissemination (Hughes, Rowe, Batey, \& Lee, 2012). However, not all professionals use social media in the same way. Social media relationships differ between strong-ties and weak-ties type users. Strong-ties type users consider their online social networks to be as "real" and interactive as their offline interactions; for the weak-ties users, "the online network can be something qualitatively different, where privacy is virtually non-existent” (Skågeby, 2012, p. 332). In both cases, their networks are carefully selected. In the weak-ties framework, an individual's network comprises weak-ties (acquaintances) and strong-ties (close family and friends). One advantage of the weak-ties framework is that weak-ties are more useful sources of new information, because individuals with strong-ties usually possess the same information as other members of the network. Hence, weak-ties type users have a wider network, but not much personal interaction or participation in that network. Skågeby (2012) has conducted ethnographic studies of Facebook, Flickr and a music-sharing site; however, the users examined in that study were not part of a professional network. It would be useful to explore, as this current study does, whether information technology (IT) professionals, who can be assumed to be more familiar with the privacy and security implications of social media, have similar perceptions when using Twitter.

The literature confirms that online spaces enable online collaboration, facilitate social interaction and attract wider audiences as well as participants worldwide. Microblogs support online collaboration that is independent of time and place (Ebner, Lienhardt, Rohs, \& Meyer, 2010). This is because microblogs are perceived as places, comparable to physical spaces, that engender a sense of belonging that enable IT professionals to create communities of practice. This is consistent with extant research findings that Twitter is a flexible and powerful electronic form of word-of-mouth communication channel for sharing and disseminating information (Jansen, Zhang, Sobel, \& Chowdury, 2009). It allows users to repurpose the tool to suit their needs (Straumsheim, 2014). The flexibility and usability of Twitter encourage IT professionals to use it for professional purposes. Twitter has helped IT professionals to share their knowledge and create communities of practice much more easily compared to offline information grounds. An information ground refers to a public (and physical) social setting where people go to carry out everyday life activities such as eating and hairdressing, but ultimately end up engaging in seeking and sharing of information (Fisher, Landry, \& Naumer, 2007). An offline information ground is often restricted to a certain group of experts who can participate in the discussion, whereas online information grounds allow experts around the world to participate in the group discussion. This scenario suggests that Twitter increases the chances for IT professionals to be acknowledged as experts in their fields.

Narayan (2013) suggested that social media platforms are perceived as places that are comparable to physical spaces. Power (2015) noted that microblogs help IT professionals' career development and facilitate their creation of communities of practice. This is consistent with Fischer and Reuber (2011) findings that social interaction occurs dynamically and are less time-consuming, "yet oriented less than Facebook towards the entrepreneur's personal network" (p. 3). This is because "entrepreneurs can use Twitter to broadcast a link to their blog and send their Twitter messages automatically to their Facebook page" (Fischer \& Reuber, 2011, p. 3). The literature reveals no previous empirical study of microblogging platforms as "places" and how they influence information behaviour in online spaces. This 
study aims to fill that research gap. The main research question that this study will address is: what are IT professionals' information-related behaviours on Twitter.

\section{RELATED WORKS}

Previous research related to the current investigation has focused on three areas: studies about strength of weak ties, incidental acquisition of information, and IT professionals' use of Twitter for professional purposes.

\section{The Strength-of-Weak-Ties Framework}

The strength-of-weak-ties framework was developed to provide a fundamental understanding of micro-level interactions to macro-level patterns in a convincing way. There is an abundance of quantitative and qualitative studies that provide significant insights into macro and micro-level phenomena. However, the question of "how interaction in small groups aggregates to form large-scale patterns" had not been clearly discussed in social science arenas and "eludes [sociologist perspectives] in most cases" (Granovetter, 1973, p. 1360). The macro phenomena were identified as "social mobility, community organization, and political structure” (Granovetter, 1973, p. 1360). On the other hand, “a large and increasing body of data and theory offers useful and illuminating ideas about what transpires within the confines of the small group” (p. 1360) or at the micro level (Granovetter, 1973). The strength-of-weakties framework suggests that any individual's network comprises weak-ties (acquaintances) and strong-ties (close family, friends), but proposes that weak-ties are more useful sources of new information because strong-tie sources usually possess the same information as the individual.

Pettigrew's (1998) information grounds theory was based on Granovetter's (1973) strength-of-weak-ties framework. Pettigrew (1999) tested the strength-of-weak-ties within the health community and revealed that the nurse is a weak-tie who can provide valuable information regarding health information services that a doctor cannot obtain through their own strong-ties. Granovetter (1973) drew attention to the fact that weak-ties play a more significant role than strong-ties within personal information networks. According to Pettigrew (1999), weak-ties act as "local bridges" that facilitate information networks to connect individuals who are situated in different social networks. Strong-ties act as information validators to certify the value, relevance and usefulness of new information (Pettigrew, 1999). In short, people who are already in one's own circle are likely to think in the same manner as oneself; people further off in the network are more likely to have new or different information, which could be potentially valuable.

In terms of social networks, this theory can be interpreted in the following mannerbroad and diverse networks with weak-ties are a richer source of new information than narrow and homogenous networks with merely strong-tie connections. The weak-tie connections play a significant role in social media as they contribute new information compared to strong-tie connections, which are generally restricted to a certain number of people or a group of people within the networks. Consequently, the weak-tie connections have a huge impact on the development of social networks.

Nielsen (2006) developed a theory of participation inequality in the context of online social networks based on the findings that $90 \%$ of all users are "lurkers", $9 \%$ of all users contribute occasionally but repost the contributions of the one percent who contribute the most often, and $1 \%$ of all users participate significantly and account for most of the content in 
the community. When we connect Granovetter's theory of the strength-of-weak-ties to Nielsen's 90-9-1 rule, it can be inferred that the $90 \%$ of users do have a significant influence in these networks, as they comprise most of the audience of the networks. It is argued that the $9 \%$ act as the glue to hold the network together as they have a high number of interactions. Furthermore, the $9 \%$ aid the way in which information is shared and spread across the network. These percentages reflect the rich, complex and dynamic way in which social media are used for both personal and professional purposes. The current study seeks to find out how the $9 \%$ of social media users influence the use of social media for professional purposes.

\section{Incidental Acquisition of Information}

Williamson (1998) pointed out that "incidental information acquisition" is synonymous with "accidental information discovery" (p. 24). This implies that people find information unexpectedly as they engage in other activities, where some of the information they find is "information they did not know they needed until they heard or read it" (Williamson, 1998, p. 24). Erdelez (1997) used the term "information encountering" for "memorable experiences of accidental discovery of useful or interesting information” (Erdelez, 1997, p. 412). Recently, Workman, Fiszman, and Rindflesch (2014) found four important themes in the field of serendipitous knowledge discovery, specifically: iteration; change or clarification; a seeker's prior knowledge; and the role of information organisation and presentation. These identified themes play an important role in the serendipity of knowledge discovery while seeking information (Workman, Fiszman, \& Rindflesch, 2014). The term "serendipity" refers to an unexpected information discovery made while seeking information (Foster \& Ford, 2003) and commonly occurs while people interact or engage in physical face-to-face communication (Fisher, 2005).

Wilson (1999) highlighted that people frequently discover new information while monitoring their world in an attempt to keep themselves up to date. This also arises while they monitor their world in a mobile-based environment and is more likely to occur while they engage and communicate with their community (Counts \& Fisher, 2010). A mobile-based environment is similar to that of microblogging. However, the difference lies in the availability of and accessibility to information, making the incidence of serendipitous information-encountering or information-sharing higher. According to McNely (2009), Twitter is an information-rich space in which the serendipity of information-encountering and information-sharing is highly likely to occur and may influence the information behaviour of IT professionals on Twitter.

Twitter was originally developed for the purposes of casual social communication rather than to spread and seek timely news (Eisenberg, Lin, Marino, \& Karlova, 2011). Over time, the use of Twitter has changed from personal use to professional use in various perspectives (e.g. networking, collaboration or knowledge-sharing) (Power, 2015). Twitter enables users to stay connected to their friends, family members and co-workers (Huberman, Romero, \& Wu, 2009). Accordingly, that has a significant influence upon serendipitous information-seeking (Ostrander, 2008) and serendipity of information-encountering on Twitter as the networks are wider (Workman, Fiszman, \& Rindflesch, 2014). This current study aims in part to investigate the incidental acquisition of information on Twitter. 


\section{Use of Twitter by IT Professionals for Professional Purposes}

Twitter is a microblogging service where IT professionals can share short messages known as "tweets" that contain no more than 140 characters. Tweets can also include links to blogs, Web pages, images, videos, and articles, as well as acting as a platform for live events such as conferences. Twitter helps IT professionals to disseminate valuable information to a wider audience via posts of up to 140 characters in length per message. This creates brevity of communication (Miller, 2008) where there is "freedom within such restriction" (Schirmer, 2011, p. 24). This restriction also enables IT professionals to announce and share information regarding their own works. Moreover, such restrictions actually help IT professionals to promote their expertise and share their blog post updates, since Twitter acts as a gateway to other social media applications (Miller, 2008).

Twitter has become acknowledged as the most powerful of microblog that not only enables IT professionals to share information and their knowledge to wider audiences, but also helps them to create professional networks and collaborative works. Murphy (2008) emphasised that the more friends who are added or "followed" by subscribing to others' feeds, the more visible the account will be. IT professionals can build their professional network by searching for an expert in their field through username, email, location and interests on Twitter. Power (2015) noted that Twitter will create a profile for users, but an individual's decision whether to follow or not will be based on the profile and bio that is created and shared on Twitter. It is important for IT professionals to create an online persona that reflects their professional context by providing relevant areas of interest and/or expertise (Power, 2015). Creating an online persona in microblogging helps IT professionals to create their network and appeal to people with common interests.

Twitter was originally developed for casual communication and has also been used for personal communication. Recently, it has been adopted and used by IT professionals, health professionals and academics to communicate, access, share and disseminate professional information (Power, 2015). Twitter potentially enhances professional networking opportunities as it provides an opportunity to "meet” both experienced and novice tweeters. Via this forum, professionals can support and inform other professionals so as to deliver better services (Power, 2015). The key benefits of Twitter include the capability to be multifocal, immediate, connecting and mobile (Torrente, Martí, \& Escarrabill, 2012), thereby having a significant impact on the development of professional networks. The term "multifocal" indicates both the diversity of information and the variety of sources of information available. In order to reduce information overload on Twitter, Power (2015) argued that "hashtags are commonly used to categorise or signpost tweets and organise Twitter feeds" subsequently helping professionals to facilitate engagement with an intended audience. Hashtags are used to emphasise particular messages, but users do not really use the hashtag function in a strategic way (Letierce, Passant, Decker, \& Breslin, 2010). It has been discovered that they merely use it because it is a well-known practice on Twitter. This study, however, did not investigate the use of hashtags for professional development, as the principal aim was to understand microblogs as a place for professional communication rather than focusing on specific features of Twitter.

Murphy (2008) emphasised that sharing best practices and working collaboratively via Twitter has significantly enhanced the function of library services. It is important for libraries to continue to explore and incorporate new emerging technologies to deliver better services. Twitter enables IT professionals to create their own communities of practice that allow them to keep in-touch with experts and to ensure that they are up-to-date with information. Tian 
and Lo (2014) discovered that the use of Twitter is widespread in the software engineering community to help these professional keep in-touch with experts in their fields and remain upto-date with new information. Software engineers' tweets commonly contain job openings, news, questions and answers, or links to download new tools and codes (Tian \& Lo, 2014).

\section{RESEARCH METHOD}

For the purpose of this study, Twitter was chosen over Facebook and other platforms because Twitter is more open than Facebook and less restrictive: Twitter does not require mutual sharing. Facebook generally connects friends or people who already know each other, whereas Twitter connects friends and strangers with common topical interests. In choosing Twitter, this study aimed to learn whether or not the microblogging phenomenon was different from traditional methods of information communication in the context of IT professionals using Twitter for professional purposes.

This study adopted online observation and interview for data collection. The data were analysed using constructivist grounded theory. The online observation helped the researcher to discern the information behaviours - observable actions of the participants as well as objectives inferred from the post content. This was followed up with interviews to gain an indepth understanding of the participants' thoughts, feelings and motivations. The participants' interview transcripts were analysed until saturation was reached based on grounded theory methods (Dick, 2005). In the grounded theory method, saturation is achieved when no new findings emerge from the data, and the same codes begin to appear over and over again.

This study focused on Information Technology (IT) professionals who use Twitter for professional purposes. The participants were practitioners, academics, government employees, and researchers. This study did not investigate the validity of the content tweeted by participants and did not perform a background check for each individual who identified himself or herself as an IT professionals on Twitter. IT professionals in this study identified themselves as individuals who work in the IT fields or as IT support to top management in their respective organisations. To ensure the credibility and reliability of the data, the population was selected carefully. First, the researcher examined the participants' account to determine whether or not they had been using Twitter for at least six months and tweeted or retweeted information relevant to his or her stated work area. For example, if the participant was working on information security, they might have shared information about new technology for security or they might have a conversation about that on Twitter. Second, the researcher checked each participant's timeline to ensure that the participant shared more work-related information than personal information. Sometimes, participants shared information about entertainment news, current affairs, weather or sports along with some personal context, but they were not excluded. Third, the researcher contacted participants who agreed to participate in this study to confirm their job title and determine whether or not they were working in an IT or IT-related field. However, this study did not authenticate the participants' self-declared job designation and job description.

Eleven IT professionals were identified and "followed" online for two weeks between 1 September 2013 and 31 December 2013, and their tweets were downloaded with their permission. A total of 734 tweets were downloaded and analysed using a constructivist grounded theory approach. The tweets were coded and categorised, and constantly compared between participants and between codes. This enabled the emergent findings from the data to arise organically. In addition, the participants' information behaviours were documented explicitly. The connection between the participants' tweets and information behaviour 
enabled the researcher to develop effective interview questions to better understand the participants' personal experiences and to examine the extent to which they used Twitter for professional networking rather than just as a part of their job description (e.g. social media policy-maker or social media manager). After following the participants on Twitter for two weeks, each participant was contacted for a one-on-one interview. Each of the interview lasted 30 to 60 minutes. The interviews were coded until the emergent categories were saturated (Charmaz, 2006).

\section{FINDINGS}

Discussion of the findings are divided into five themes: information-sharing behaviour, social and professional networking, online identity/image/profile/presence, development of weak-tie to strong-tie relationship, and relationship between professional networking and information transfer.

\section{Information-Sharing Behaviour}

Microblogging sites provide online platforms for participants to share information, as well as encounter, seek and use the shared information. The results of the study indicate that information sharing and use are of primary importance in the microblogging sphere.

Participants share interesting information and often add their own comments before sharing it. As Participant 7 stated:

If I want to re-tweet something and I think it's stupid or out of line or inappropriate, I always add some kind of text that says 'this is ridiculous' and then tweet it. But, in general, I try to add some kind of commentary to links before I tweet them. (P7)

Participants often add comments to show their agreement on or endorsement of a particular post.

Some participants did not bother to modify the information (tweets) or add their own thoughts or opinions. This was because they only "re-tweet if the information is good for sharing” (P6), or if they agree with it, as indicated by Participant 3:

Every now and then I'll see something on Twitter where someone has tweeted their opinion or put up a blog post about something. If that resonates with me for some particular reason, then I'll often re-tweet. (P3)

Participants recognize that the information they encounter or share may be valuable for their followers, and are cognizant of the need to validate the source of information before posting it. As Participant 6 said in the interview:

I need to confirm whether the information that I'm going to tweet is correct so I filter it by reading the article. If I find out that it's something new, I'll continue further on my discovery and if there is something wrong with the links to the articles, then I don't share it on Twitter. (P6)

The participants read through the information before sending it out from their Twitter accounts and ensured the links to the resources were correct before sharing. Participant 1 explained this as follows:

A lot of technical information will be valid because I am familiar with this material. I click on it and read it and then decide whether it is definitely valid. (P1) 
Aside from using their own judgment of the validity of information, they also considered the usefulness of the information to themselves and used that as an indicator of potential usefulness to others. Participant 11 explained it this way:

Those links that were originally tweeted by me were those that I have read. I found that if it is valuable for me then it might also be beneficial for somebody else. (P11)

The participants revealed that they checked the authenticity of the information and ensured that the links to the information were not broken. Participant 6 described this as follows:

I'm really concerned about the authentication of information or if there is a broken link before I share something on Twitter. Information validation is vitally important, as the truth and something false might look alike, but [the authentication] depends on my own judgment as to which one I should choose. (P6)

Participants also agreed that it was pointless if their followers could not gain access to the correct resources for reasons such as "paywalls" or geographical restrictions such as those found on newspapers or YouTube sites.

These results highlight that information validation is a key element in sharing information on Twitter. The participants carefully investigated the origin and source of the information, and read, assessed and filtered the content before sharing on Twitter to avoid the risk of their reputations being affected. For example, according to Participant 6:

I filtered it by reading the article. If I found out that it's something new, I'll continue further on my discovery. If it happens that there is something wrong with the information, especially the links to the article, then I don't share it on Twitter. (P6)

Participant 7 explained that she might have a particular person in mind when retweeting a post:

I think, for me, I generally share something because I've either read it, I'm interested in it and I think it's useful and I want to share it with people. For example, if I know my friend is interested in ' $X$ ' topic and I see an article and I think it might be interesting, I won't necessarily read it. I'll re-tweet it and say have you seen this and mention the person in it. (P7)

The outcomes of this study are consistent with those of previous studies, which indicated that personal information-sharing predominantly occurred on Twitter (Java, Song, Finin, \& Tseng, 2007). However, this study has also discovered that the way in which IT professionals share personal experiences on Twitter can also be related to their work. The interviews showed that the participants' work as information professionals played an important part in the way they shared information or opinions. For example, Participant 4 shared her thoughts on the Brisbane Film Festival because she believed that her opinions would be documented for future reference:

I actually tweeted to the Brisbane Film Festival, and I wanted to make sure [that the organisation would document the tweets]. I know from working in a library how much of an impact the documented opinions of people and organisations have, and the value of them. I tend to tweet to organisations to say, "It's great, keep up the good work". So, if it can be documented that there are people who appreciate this as citizens, that's why I decide [to tweet]. (P4) 


\section{Social and Professional Networking}

Microblogging was originally developed for the purposes of casual communication; however, it is increasingly being used in professional contexts since Twitter enables professionals to stay connected to their friends, family members and co-workers (Eisenberg, Lin, Marino, \& Karlova, 2011). The findings show that personal and professional uses of microblogging are intersecting or happening concurrently, as IT professionals share information about leisure, hobbies or day-to-day life experiences. As Participant 3 stated:

I started using Twitter for [professional reasons] because it is social technology and it is my social technology. I also use [Twitter] for personal or social reasons to share amusing things or things that I found annoying or just things that I'm doing at a point in time. So, I guess it's a bit more mixed with my personality and my activities; both at work and out of work. (P3)

In addition, Participant 5 highlighted that Twitter had a significant influence in creating professional networking:

My colleagues [are] currently on Twitter. So, I follow them and see what they're tweeting and, yes, it's just a way to keep in-touch with them. (P5)

Over time, Twitter helps IT professionals maintain their professional network. Participant 7 explained this as follows:

I'm really conscious of maintaining connections I've got on Twitter; they are mutually beneficial relationships. For example, over the last 6 months when I haven't really been teaching and haven't done any speaking or gone to any conferences, it's really important for me to be able to keep in-touch with those people so that those networks remain intact when I'm back doing my normal job. (P7)

Participant 8 mentioned in the interview that Twitter was a good space for creating and maintaining professional network connections in various ways:

I don't really interact with people a lot through Twitter but it's a good space to keep a record of people that you perhaps meet at conferences or things like that. Also, you can stay in-touch with them and not have to invite them into your Facebook. (P8)

\section{Online Identity/Image/Profile/Presence}

This study highlights the issue that information shared via microblogging will reflect on the IT professionals' identity and affect their online presence. The participants tended to consider their online presence to be as important as their physical presence. Moreover, they believed that it was important for them to ensure they did not inadvertently share something that could damage their online professional persona. Participant 5 pointed out that she would not be posting anything that contained controversial issues or could cause arguments:

I generally tweet things that are safe. They're not very controversial. They are sort of interesting to me and to the people who may be following me. I don't tweet anything that's going to cause any arguments as that would look bad professionally and I certainly wouldn't like to tweet anything unprofessional. (P5)

This study also reveals that IT professionals use microblogging as a tool to establish a presence online and to be acknowledged as an expert in a particular field. As Participant 1 explained in the interview: "in a professional respect, Twitter has actually been quite good 
because it has a social presence” (P1). It has also enabled IT professionals to put their profiles on Twitter, as "it is important to have a professional profile within Twitter." (P3)

This finding maps well to Erwing Goffman's (1971) theory of representation of self in everyday life, as the projection of self-image on social media is achieved through online presence rather than using body language and verbalism. This study highlights that the important elements of self-representation in online spaces are honesty and transparency in knowledge and information-sharing. Participant 11 also pointed out that he would not post negative opinions that were vague or not well-thought out:

I [decide to tweet] if a paper contains something personal or something which could be of value. For example, sometimes I feel like writing, 'Oh, I read your paper, but I think it has a flaw'. However, I'm not going to write that the paper is flawed if I don't really realise why it's flawed but I just have a feeling. (P11)

\section{From Weak-Tie to Strong-Tie Relationship}

The participants pointed out that information-seeking and sharing could lead to the formation of human networks, and develop into cooperative and collaborative relationships on more private platforms. Participant 11 explained it this way:

Information-gathering and information-sharing started on Twitter then ended up on email or something else. [...] Most of the discussion is basically something that is not meant to be public, so it's something like planning of the year or planning of projects. Maybe some algorithm needs to be implemented in the code, so we can choose not to make it public. That's why we come up with another platform. (P11)

Participant 7 published a collaborative paper with a researcher in the library and information science field whom she met on Twitter before they officially met face-to-face in a work environment:

I'm connected to [Person A] as we used to use direct messages on Twitter before we physically met. So, I think the first time I met her was maybe 18 months after we met on Twitter and we were already collaborating on research at that point before she came to work with us. (P7)

\section{Relation Between Professional Networking and Information Transfer}

Dunlap and Lowenthal (2009) and Sheehan (2013) emphasised the usefulness of microblogging for information-sharing and professional purposes, as well as the significant impact it had on social presence. This study found that microblogging is a useful tool for keeping in touch with both information and people.

The information-sharing on human networks can have an impact on participants' career development and knowledge transfer. The findings reveal that professional networking and information-sharing on Twitter are both important and are intertwined.

The IT professionals were also quite concerned about security and privacy breaches on the Internet. They frequently shared information about malware attacks and solutions that might be useful to others. For example, Participant 11, who worked in the computer security industry, was actively engaged in sharing information about the vulnerability of computer 
security and threats on the Internet:

I've followed a guy from the information security field who shares quite valuable [information] and nothing is misleading. So most of [the information he shared on Twitter] is of very good quality. [...] Often, I'll re-tweet those links that might be beneficial to others in the information security area. (P11)

This demonstrates that IT professionals frequently share information from other trusted people in their network if it is related to their work. Participant 6 tended to share information about privacy and security on the Internet because of the nature of his work:

I tweet about malware or the latest threat on the Internet that's helpful and useful for my followers. [...] So, first, I will check and confirm whether the information is correct. (P6)

IT products or services change rapidly over time, requiring IT professionals to stay in the information loop so as to keep up-to-date with new developments. IT professionals often seek and share information that is related to their expertise and their work because they "have a tendency to re-tweet those things and talk about those things on Twitter.” (P2)

Twitter has helped IT professionals to remain informed and up-to-date with news about technology in education as well. This was essential for Participant 7 in her lecturing and research:

A couple of people I follow post really great technology links all the time about news, articles and things that are really [about] educational technology stuff. It's material to do with mobile devices, online services, and emerging technology that I could use in my teaching and my research. (P7)

Participant 3 pointed out that microblogging helped him to keep in-touch with the latest information and also with the experts. In addition, he had received valuable information that led to professional network development:

I'd follow a professor or some academics who I respect. I wanted to read their work and then they would follow me. The relationship that I found there was really good because you can develop a bit of a [professional] profile. (P3)

Participant 4 highlighted that she stumbled upon information that led to mutual relationships with experts in her field:

Sometimes when you see something being re-tweeted by somebody else, you might look at their Twitter feeds to see if it's interesting. So, I follow and tend to have conversations. I've found it is quite a good way of networking with other people. (P4)

This finding demonstrates that Twitter acts as an information agent to assist IT professionals by indirectly extending their professional network connections. As Participant 3 said in the interview:

[Twitter] is most beneficial from a professional point of view for gaining access to articles and publications. In a way, I'm always served with those research publications instead of me having to go and find them. If someone has a new publication that might have just been published that week, I can easily get it off that hyperlink or I can ask them directly for the paper. (P3) 
It is evident that microblogging aids in participants' online presence and impacts individuals' virtual presentation of themselves as experts in their respective fields. As Participant 1 explained in the interview:

When I follow and re-tweet something related to my area, occasionally I get asked to contribute in my own field of expertise to different newsletters that are not necessarily based in Brisbane or even Australia. It also helps you become knowledgeable in the area so that you can comment on it at an international level on Twitter. (P1)

Sharing valuable and quality information through microblogging highlights the individual which may lead to the establishment of professional networks and research collaborations. Participant 3 pointed out that he valued individuals' expertise on Twitter based on their tweets:

There's a certain group of people on Twitter that I take a lot of notice of when they tweet something with a link to a research article or some industry or some observation. I'll take a look for those conversations in the threads as I scan the Twitter's stream. I'm at the stage now where I'm even thinking of having a bit of a clean up to get rid of some connections that I don't get any value out of. (P3)

Participant 7 also emphasised the importance of sharing, through microblogging, quality information that had significant impact on human networks:

I guess it's also about having a relationship with people and knowing that what they're sharing with you is quality. I kind of validate people's credentials and ask if they actually know what they're talking about. (P7)

This was because the information found in microblogging lasts longer than that of a closed network medium. To that extent, it is essential for IT professionals to showcase their proficiency by sharing information related to their field of expertise.

Twitter helps IT professionals to disseminate their knowledge and broadcast their knowledge-sharing to the world. Understandably, Twitter is a powerful electronic word-ofmouth tool (Jansen, Zhang, Sobel, \& Chowdury, 2009) that can increase the scope and breadth of an individual's reach within any given professional context. Knowledge and information-sharing occurs dynamically in online spaces in the following ways: from one-toone to one-to-many; one-to-many to many-to-many; and interdisciplinary to multidisciplinary. This is in contrast to physical environments that are linear and limited to one genre. As Participant 2 explained in the interview:

In doing some business development for my company and sharing my knowledge, I talk to a number of different people on Twitter in regards to generating business and other matters. (P2)

Participant 5 pointed out that Twitter was useful for organising events and collaborating with researchers and developers in their fields including digital humanity, library and information science (LIS), as well as software engineering. This also aided the participant's online presence and led her to professional networking opportunities when she consistently used Twitter for event organisation and collaboration:

I organise events and I work on projects that have international collaborators from the digital humanity community, library community, and software engineering community. [...] Direct messages are used to discuss details of the next event or something like that and to keep in-touch with the research community and the developer community. (P5) 
The results of the present study map well to Granovetter's (1973) strength-of-weak-ties theory. This theory suggests that any individual's network comprises weak-ties (acquaintances) and strong-ties (close family, friends), but that weak-ties are useful sources of new information. In a microblogging context, there can be a very large number of such weaktie links. As Participant 3 explained, "I'm following 18,000 handles and I'm getting value out of maybe half of those connections" in that "I'm looking forward to reading their contributions.”

The weak-tie relationships can be used to organize physical events, recruit staff and customers, and mobilize people for a project. As Participant 9 said in the interview:

I [organised] Brisbane Twitter Underground Brigade Christmas parties here at my house. [...] I had previously only met them through Twitter, but I've now met them over the last year or two so I got to know them. But some people who came here, I never met them. (P9)

Participant 9 also found new clients and recruited new staff members from his involvement with the community on Twitter:

I found [Twitter] really useful to become involved with potential clients, recruiters and finding staff. It's basically helped me to keep informed of what other people are doing and what's happening, what's new. (P9)

Participant 7 highlighted that Twitter helped to support her virtual office:

I interact with [Person A] on [Twitter] and just people that I've worked with in the past at other organisations, so, I guess it's really like my virtual office. (P7)

The participants also pointed out that they used Twitter to share and obtain professional information from their weak-tie networks, and interact with their strong-tie connections on the social networking site Facebook:

I use Facebook, but that's pretty well more for private life. (P4)

Similarly, Participant 6 said in the interview, "I connect with my friends using Facebook while I use Twitter to share information related to my work.” (P6) Participant 1 emphasised that he used Facebook for personal purposes more so than Twitter:

I use Facebook more for personal reasons [as] I share fun stuff and activities and [in turn] my friends share pictures of their kids and that sort of stuff. (P1)

The findings of this study have revealed that Twitter can be considered a public space that helps IT professionals to develop their information grounds in online spaces. The availability of information and people are beyond that which traditional information grounds can offer. Their information behaviour and social interaction on Twitter significantly influence their self-representation and the dynamic nature of the microblogging information ground. IT professionals' information behaviour in microblogging has an impact on the way they use Twitter for professional purposes.

\section{CONCLUSION}

The way in which Twitter enables information-sharing to occur dynamically and in a less time-consuming fashion has a significant influence on the way IT professionals use Twitter for professional purposes. The findings reveal that professional networking and professional work are the main intent of IT professionals when using Twitter. Social and professional 
networking on Twitter has helped IT professionals maintain their professional networks, create their online presence, and establish their professional connections from weak to strongtie relationships. This study also highlighted the importance, merits and inter-relatedness of information-sharing and professional networking. In other words, such a relationship between social networking and information transfer on Twitter has significant influence upon information flow in microblogging.

The information flows have significantly helped IT professionals' to expand their professional networks and facilitate communities of practice. This finding is consistent with that of Jansen, Zhang, Sobel, and Chowdury (2009) who stated that Twitter is more about creating connections with others who may not be real friends. IT professionals go to Twitter to keep in-touch with colleagues and also for professional development, rather than merely to gather or share information.

This study has yielded an interesting result that information acts as a trigger to create human networks in microblogging since encountering and sharing information are more likely to help IT professionals to discover experts' contacts serendipitously. This scenario occurred due to the complexity of networks, and hence the information that has been shared on Twitter can reach wider audiences. This observation is consistent with Erdelez (1999) who suggested that serendipitous information encounter often occurs when people interact and share information. Furthermore, people often come across information unexpectedly as they engage in other activities, which leads them to the "information they did not know they needed until they heard or read it” (Williamson, 1998, p. 24).

The findings also suggest that the information grounds theory (Fisher, 2005) is applicable to Twitter networks. The information grounds theory posits that a space becomes conducive to rich information exchange wherever people, place and information meet-for information to be generated dynamically and in a serendipitous manner. More importantly, this serendipity applies not just to information encountering, but also to encountering experts and even work and project opportunities.

Re-tweeting is a form of conversation in Twitter that has transformed the way people communicate in online spaces. The action of re-tweeting significantly triggers social interaction with weak-tie connections. Weak-ties users are different to strong-ties users within the online network, and privacy is virtually non-existent for the weak-ties users (Pettigrew, 1998). Weak-tie connections are often useful sources of new information. This finding is consistent with Skågeby (2012) who described weak-ties type users as being different from strong-ties type users. The notable difference is that strong-ties types users consider their online social networks to be as "real" and interactive as their offline interactions, where their networks are carefully selected. Pan and Saramäki (2012) argued that strong-tie networks are important for enhancing information flow across scientific collaboration networks within a closed network. This study investigated the information behaviour of IT professionals' in the context of Twitter only. IT professionals engage more with weak-tie than strong-tie connections on Twitter, as they use Twitter heavily for professional purposes rather than for personal use.

This study revealed that the complexity of the networks has helped IT professionals to expand their professional networks. Following experts on Twitter will sooner or later be fruitful. The more IT professionals share information that is related to his or her expertise, the greater the chance to be noticed or acknowledged as an expert on Twitter. IT professionals also tend to establish their professional networks by authenticating the experts whom they unexpectedly discover on Twitter by performing background checks via Google search engine and LinkedIn before following them. 
The study has shed some light on how Twitter is used for professional purposes. The findings can assist organisations to better understand and provide for this emerging channel of professional information-sharing for their staff and stakeholders.

\section{REFERENCES}

Bartlett, J. C., \& Toms, E. G. (2005). How is information used? Applying task analysis to understanding information use. In Proceedings of the 35th Annual Conference of the Canadian Association for Information Science. Retrieved from http://www.caisacsi.ca/ojs/index.php/cais/article/download/159/653

Bates, M. J. (1990). Where should the person stop and the information search interface start? Information Processing \& Management, 26, 575-591.

Bates, M. J. (2005). An introduction to metatheories, theories, and models. In K. E. Fisher, S. Erdelez \& L. E. F. McKechnie (Eds.), Theories of Information Behavior (pp. 1-24). Medford, NJ: ASIST Monograph Series.

Belkin, N. J. (2008). Some(what) grand challenges for information retrieval. SIGIR Forum, 42(1), 47-54.

Charmaz, K. (2006). Constructing grounded theory. London: Sage Publications, Inc.

Chatman, E. A. (1991). Life in a small world: Applicability of gratification theory to information-seeking behavior. Journal of the American Society for Information Science, 42, 438-449.

Counts, S., \& Fisher, K. E. (2010). Mobile social networking as information ground: A case study. Library \& Information Science Research, 32, 98-115.

Dick, B. (2005). Grounded theory: A thumbnail sketch. Retrieved from http://www.aral.com.au/resources/grounded.html - a_gt_sat

Dunlap, J. C., \& Lowenthal, P. R. (2009). Tweeting the night away: Using Twitter to enhance social presence. Journal of Information Systems Education, 20(2), 129-135.

Ebner, M., Lienhardt, C., Rohs, M., \& Meyer, I. (2010). Microblogs in higher education - A chance to facilitate informal and process-oriented learning? Computers \& Education, 55, 92-100.

Eisenberg, M. B., Lin, P., Marino, J., \& Karlova, N. (2011). Research on credibility and immersive virtual environments virtual information behavior environments (VIBE) project. Retrieved from http://faculty.washington.edu/mbe/Eisenberg-VIBE ProjectFinal Narrative Report-Dec 2011.pdf

Erdelez, S. (1997). Information encountering: A conceptual framework for accidental information seeking. Paper presented at the International Conference on Research in Information Needs, Seeking, and Use in Different Contexts, Tampere, Finland.

Erdelez, S. (1999). Information encountering: It's more than just bumping into information. Bulletin of the American Society for Information Science, 25(3), 25-29.

Fisher, K. E. (2005). Information grounds. In K. E. Fisher, S. Erdelez \& L. E. F. McKechnie (Eds.), Theories of information behavior (pp. 185-190). Medford, NJ: ASIST Monograph Series.

Fisher, K. E., Landry, C. , \& Naumer, C. M. (2007). Social spaces, casual interactions, meaningful exchanges: "Information ground" characteristics based on the collage student experience. Information Research, 2(12). Retrieved from http://informationr.net/ir/12-2/paper291.html 
Fischer, E., \& Reuber, A. R. (2011). Social interaction via new social media: (How) can interactions on Twitter affect effectual thinking and behavior? Journal of Business Venturing, 26, 1-18.

Foster, A., \& Ford, N. (2003). Serendipity and information seeking: An empirical study. Journal of Documentation, 59(3), 321-340.

Goffman, E. (1971). The presentation of self in everyday life. Harmondsworth: Penguin. Granovetter, M. (1973). The strength of weak ties. American Journal of Sociology, 78(6), 1360-1380.

Huberman, B. A., Romero, D. M., \& Wu, F. (2009). Social networks that matter Twitter under the microscope. First Monday, 14(1).

Hughes, D. J., Rowe, M., Batey, M., \& Lee, A. (2012). A tale of two sites: Twitter vs. Facebook and the personality predictors of social media usage. Computers in Human Behavior, 28, 561-569.

Jansen, B. J., Zhang, M., Sobel, K. , \& Chowdury, A. (2009). Twitter power: Tweets as electronic word of mouth. Journal of the American Society for Information Science and Technology, 60(11), 2169-2188.

Java, A., Song, X., Finin, T., \& Tseng, B. (2007). Why we Twitter: Understanding microblogging usage and communities. In Proceedings of the 9th WebKDD and 1st SNA-KDD 2007 Workshop on Web Mining and Social Network Analysis, San Jose, CA, USA.

Letierce, J., Passant, A., Decker, S., \& Breslin, J. G. (2010). Understanding how Twitter is used to spread scientific messages. Paper presented at WebSci10: Extending the Frontiers of Society On-Line, Raleigh, NC, USA.

McNely, B. (2009). Backchannel persistence and collaborative meaning-making. In Proceedings of the 27th ACM International Conference on Design of Communication, Bloomington, Indiana, USA.

Miller, V. (2008). New media, networking and phatic culture. Convergence: The International Journal of Research into New Media Technologies, 14(4), 387-400.

Murphy, J. (2008). Microblogging for science and technology libraries. Science \& Technology Libraries, 28(4), 375-378.

Narayan, B. (2013). From everyday information behaviours to clickable solidarity in a place called social media. Cosmopolitan Civil Societies: An Interdisciplinary Journal, 5(3), $32-53$

Nielsen, J. (2006). Jacob's column on Web usability: Participation inequality: Encouraging more users to contribute. Retrieved from http://www.useit.com/alertbox/participation_inequality.html

Ostrander, M. (2008). Talking, looking, flying, searching: Information seeking behaviour in Second Life. Library Hi Tech, 26(4), 512-524.

Pan, R. K., \& Saramäki, J. (2012). The strength of strong ties in scientific collaboration networks. EPL (Europhysics Letters), 97(1), 18007.

Pettigrew, K. E. (1998). The role of community health nurses in providing information and referral to the elderly: A study based on social network theory (Unpublished doctoral dissertation). The University of Western Ontario, Canada.

Pettigrew, K. E. (1999). Waiting for chiropody: Contextual results from an ethnographic study of the information behaviour among attendees at community clinics. Information Processing and Management, 35(6), 801-817.

Pirolli, P., \& Card, S. (1999). Information foraging. Psychological Review, 106, 643-675. 
Power, A. (2015). Twitter's potential to enhance professional networking. British Journal of Midwifery, 23(1), 65-67.

Schirmer, J. (2011). Fostering meaning and community in writing courses via social media. Cutting-edge Technologies in Higher Education, 3, 15-38.

Sheehan, C. (2013). How are professors embracing social media? Retrieved from https://teachonline.asu.edu/2013/03/how-are-professors-embracing-social-media/

Skågeby, J. (2012). The irony of serendipity: Disruptions in social information behaviour. Library Hi Tech, 30(2), 321-334.

Straumsheim, C. (2014, August 19). Twitter has the chatter. Inside Higher Education. Retrieved from https://http://www.insidehighered.com/news/2014/08/19/studyscholars-are-present-professional-networks-engage-twitter

Tian, Y., \& Lo, D. (2014). An exploratory study on software microblogger behaviors. Paper presented at the 2014 4th IEEE Workshop on Mining Unstructured Data (MUD 2014), British Columbia, Canada.

Torrente, E., Martí, T., \& Escarrabill, J. (2012). A breath of twitter. Revista Portuguesa de Pneumologia, 18(3), 137-141.

Williamson, K. (1998). Discovered by chance: The role of incidental information acquisition in an ecological model of information use. Library and Information Science Research, 20(1), 23-40.

Wilson, T. D. (1999). Models in information behaviour research. Journal of Documentation, 55(3), 249-270. Retrieved from http://informationr.net/tdw/publ/papers/1999JDoc.html

Workman, T. E., Fiszman, M., \& Rindflesch, T. C. (2014). Framing serendipitous information-seeking behavior for facilitating literature-based discovery: A proposed model. Journal of the Association for Information Science and Technology, 65(3), 501-512. 